\title{
REVIEW
}

\section{A Review of Cardiovascular Outcomes in the Treatment of People with Type 2 Diabetes}

George Dailey $\cdot$ Edward Wang

To view enhanced content go to www.diabetestherapy-open.com

Received: August 12, 2014 / Published online: December 17, 2014

(c) The Author(s) 2014. This article is published with open access at Springerlink.com

\section{ABSTRACT}

Introduction: Cardiovascular disease (CVD) is a common and serious complication of type 2 diabetes mellitus (T2DM) often linked to the increased morbidity and mortality associated with T2DM. Monitoring and treating risk factors for CVD are important elements of diabetes management. This review aims to examine CV risk in people with relatively early and mild diabetes who are at substantial risk of CVD; it considers the impact of insulin therapy on this risk by focusing on key studies in patients with diabetes.

Methods: A literature search was carried out using PubMed to identify key publications,

E. Wang was an employee of Sanofi at the time the manuscript was developed.

Electronic supplementary material The online version of this article (doi:10.1007/s13300-014-0091-x) contains supplementary material, which is available to authorized users.

G. Dailey ( $\square)$

Scripps Clinic Torrey Pines, La Jolla, CA, USA

e-mail: Dailey.George@scrippshealth.org

E. Wang

Sanofi, Bridgewater, NJ, USA between 2008 and 2013, related to insulin and its possible effect on CVD. This review examines $\mathrm{CV}$ risk in diabetes and the impact of insulin therapy on this risk.

Results: Studies have shown that treatment with insulin glargine is associated with marked improvement in the lipid profile of people with T2DM. Intensive insulin therapy has been shown to lower mortality rates in people with diabetes following acute myocardial infarction after 1 year. Retrospective data also indicate that insulin reduces the risk of CVD events, regardless of whether people had comorbidities known to increase $\mathrm{CV}$ risk. The prospective ORIGIN (Outcome Reduction with Initial Glargine Intervention) trial found that treatment with insulin glargine had a neutral effect with regard to $\mathrm{CV}$ outcomes in people with prediabetes or early diabetes, compared with standard care.

Conclusions: Other ongoing, large-scale studies of insulin therapy should provide further insights into whether or not insulin therapy can influence long-term CV outcomes.

Keywords: Cardiovascular disease; Cardiovascular risk; Glycated hemoglobin; 
Glycemic control; $\mathrm{HbA}_{1 \mathrm{c}}$; Hypoglycemia; Insulin glargine; Type 2 diabetes; Weight gain

\section{INTRODUCTION}

Elevated cardiovascular (CV) risk is a serious complication in people with type 2 diabetes mellitus (T2DM), and it is often linked to increased morbidity and mortality. Indeed, approximately two-thirds of people with T2DM die of heart disease or stroke $[1,2]$. People with diabetes often have other risk factors for cardiovascular disease (CVD), including obesity, high blood pressure and high lipid levels. Diabetes was once considered a 'risk equivalent' of CVD (i.e., that it placed people at the same risk of a cardiac event as those who had already experienced one). The measurement of glycated hemoglobin $A_{1 c}$ $\left(\mathrm{HbA}_{1 \mathrm{c}}\right)$ levels in subjects with diabetes has been shown to help predict the likelihood of CVD occurring. While $\mathrm{HbA}_{1 \mathrm{c}}$ remains an important indicator, it is the development of risk engines, in recent years, that have helped to provide a more comprehensive and graded risk of CV complications occurring in patients with diabetes based on a summary of the patient's individual risk factors [3]. Such examples include the United Kingdom Prospective Diabetes Study (UKPDS) risk engine, Oxford risk engine, a 5-year risk model developed by the Swedish National Diabetes Register and the American College of Cardiology/American Heart Association guidelines on the assessment of CV risk [4-6]. In a recent study, the association between common indicators of diabetes (postprandial glycemia, overall hyperglycemia, glucose variability, and $\mathrm{HbA}_{1 \mathrm{c}}$ level) and CVD risk factors (lipids, highsensitivity C-reactive protein, and blood pressure) was examined in people with type 1 diabetes mellitus (T1DM) and T2DM. Using linear regression models, it was found that $\mathrm{HbA}_{1 \mathrm{c}}$ showed the strongest associations with CVD risk [7]. Furthermore, in an observational, registry-based study of people with T2DM, those with tightly controlled baseline $\mathrm{HbA}_{1 \mathrm{c}}$ levels and blood pressure (median 6.5\% and $130 / 80 \mathrm{mmHg}$, respectively) had considerably decreased risks of CVD, myocardial infarction (MI), coronary heart disease (CHD), and stroke when followed for 6 years compared with individuals who did not have tight control of $\mathrm{HbA}_{1 \mathrm{c}}$ levels and blood pressure [8]. A second, similar observational study showed progressively increasing risks of CHD, CVD, and total mortality with higher $\mathrm{HbA}_{1 \mathrm{c}}$ levels [9]. This trial showed that people with baseline $\mathrm{HbA}_{1 \mathrm{c}}$ levels of $6.0-6.9 \%$ (mean $6.5 \%$ ) had a $20 \%$ lower relative risk of CHD and a $16 \%$ lower risk of CVD than people with $\mathrm{HbA}_{1 \mathrm{c}}$ levels of 7.0-7.9\% (mean 7.5\%) [9].

These observational studies demonstrate that glycemic control is linked to CV risk in people with T2DM and prospective clinical trials have been undertaken that confirm this association. It is therefore important that people with diabetes receive care that provides both good glycemic control and is optimized to deliver the best CV outcomes possible [10]. Owing to their varied mechanisms of action, different diabetes therapies are likely to have different $\mathrm{CV}$ effects. A review by Holden et al. [11] revealed that the prevalence of insulin use in the UK has risen considerably in the diabetes population and that this is primarily due to the increase in patients with T2DM using insulin, in combination with oral agents, to achieve glycemic control. A 7.5-fold increase was reported in the total number of people with T2DM using insulin in 1991 compared to 2010 (37,000 and 277,400 people, respectively) [11]. Changes in the management of T2DM have also 
occurred during this time and this has been reflected in patterns of insulin use over this period. In the USA, in 1997, 2.3 million people with diabetes were on an insulin monotherapy regimen compared to 1.1 million people on insulin combination therapy. In 2010, the number of people with diabetes on insulin monotherapy and combination therapy was 2.8 million and 2.9 million, respectively [11]. Insulin therapy is considered to be the most effective method of controlling blood glucose, but its influence beyond glycemic control is not widely appreciated. Insulin has been shown to have potent anti-inflammatory effects, to influence blood coagulation and to significantly improve measures of endothelial dysfunction. The aims of this review are to examine CV risk in people with relatively early and mild diabetes with substantial CV risk and consider the impact of insulin therapy on this risk, focusing on key studies in patients with diabetes: the UKPDS [12, 13], the Action to Control Cardiovascular Risk in Diabetes (ACCORD) [14], the Action in Diabetes and Vascular Disease: Preterax and Diamicron MR Controlled Evaluation (ADVANCE) [15], the Veteran Affairs Diabetes Trial (VADT) [16], and the Outcome Reduction with Initial Glargine Intervention (ORIGIN) [17].

\section{METHODS}

A literature search was conducted using PubMed to identify key publications between 2008 and 2013 that related to human studies of insulin and its possible impact on CV outcomes in people with T2DM. The search focused on clinical trials, meta-analyses, and relevant substudies of the trials included. Emphasis was placed on combinations of the following words as search terms: cardiovascular, CV; myocardial infarction, MI; stroke; insulin; glargine; detemir; NPH; aspart; lispro; glulisine. The search was limited to articles in the English language. The references of meta-analyses and earlier review studies investigating similar subject matter were also examined to find earlier studies of particular importance and relevance to be included in this review. The analysis in this article is based on previously conducted studies, and does not involve any new studies of human or animal subjects performed by any of the authors.

\section{UKPDS}

The UKPDS [12] investigated the effect of intensive glycemic control with either sulfonylurea or insulin compared with conventional treatment in people with newly diagnosed T2DM (Table 1). The primary endpoints investigated were risk of diabetesrelated endpoints (sudden death, death from hyperglycemia or hypoglycemia, fatal or nonfatal MI, angina, heart failure, stroke, renal failure, amputation (of at least one digit), vitreous hemorrhage, retinopathy requiring photocoagulation, blindness in one eye or cataract extraction), diabetes-related death (death from MI, stroke, peripheral vascular disease, renal disease, hyperglycemia or hypoglycemia, and sudden death), and allcause mortality over a median of 10 years. The risk of single clinical endpoints, including MI, stroke, and peripheral vascular disease, was also investigated [12].

The use of intensive treatment targeting fasting plasma glucose (FPG) $<6 \mathrm{mmol} / \mathrm{L}$ resulted in lower $\mathrm{HbA}_{1 \mathrm{c}}$ levels after 10 years (7.0\% vs. $7.9 \%)$ compared with conventional treatment (best achievable FPG on diet alone, with drugs only added if there were hyperglycemic symptoms or FPG $>15 \mathrm{mmol} / \mathrm{L}$ ) [12]. There was a trend toward reduced risk for 


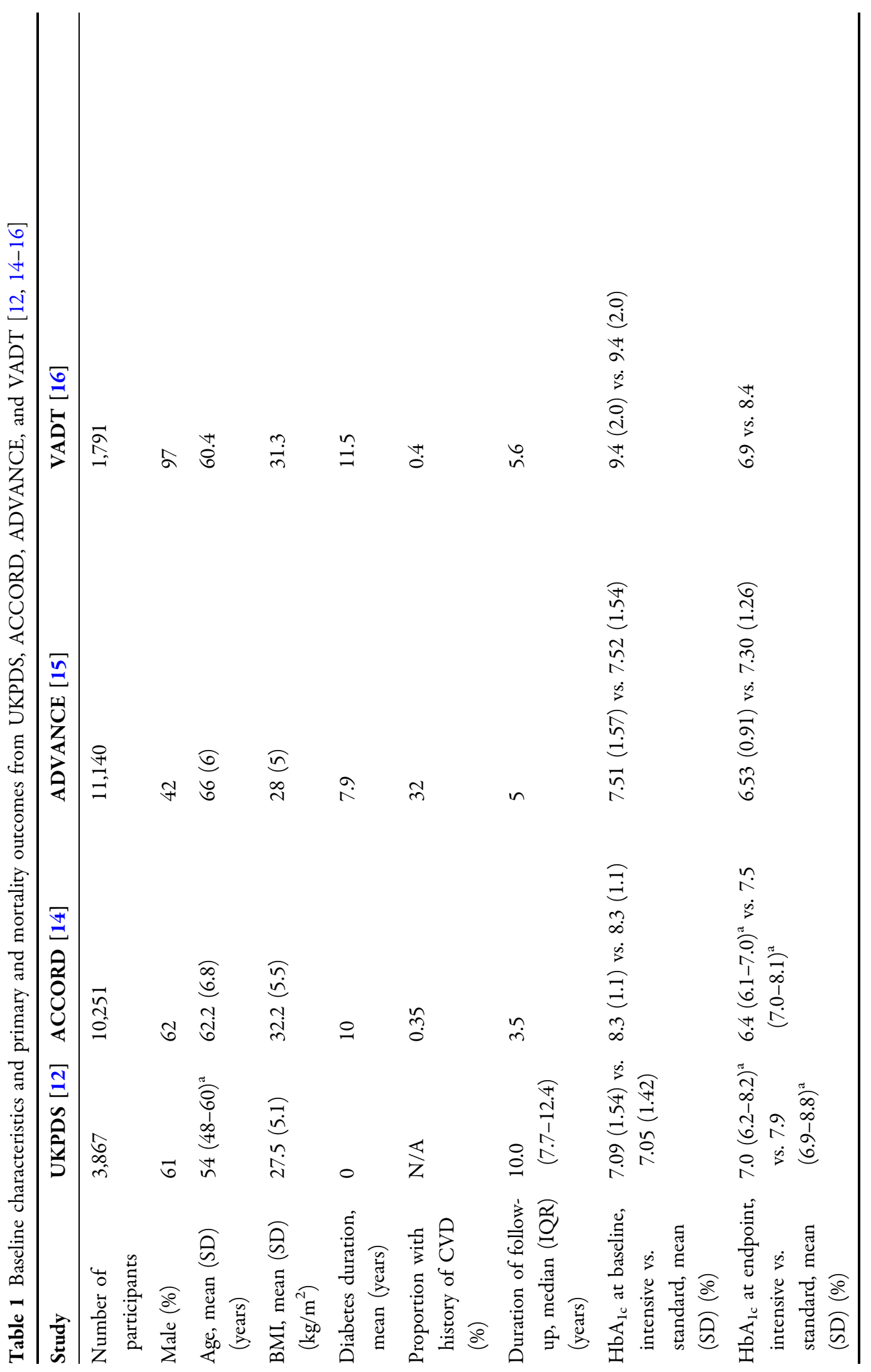




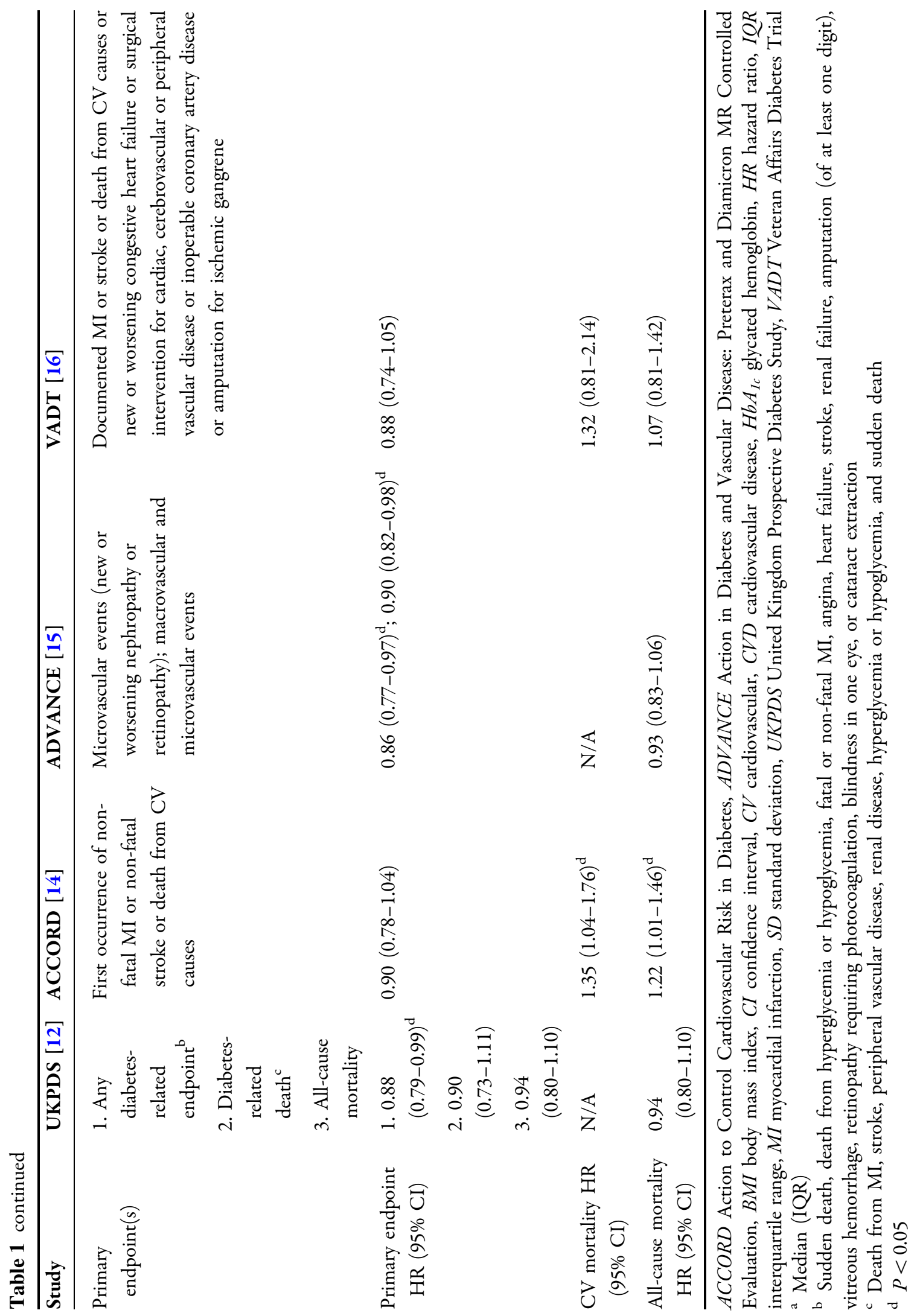


the three primary composite endpoints with intensive control compared with conventional treatment: $12 \%$ lower risk for any diabetesrelated endpoint $(P=0.029) ; 10 \%$ lower risk for diabetes-related death $(P=0.34)$; and $6 \%$ lower risk for all-cause mortality $(P=0.44)$. A $25 \%$ risk reduction for microvascular outcomes was observed with intensive treatment $(P=0.0099)$ and this was the major contributor to the reduction in risk of any diabetes-related outcomes. No risk reduction for macrovascular outcomes was observed during the 10-year treatment period of the UKPDS; however, there was a significant post-trial risk reduction for MI of $15 \%$ with intensive insulin-based therapy after a median follow-up of 16.8 years [13].

The UKPDS transformed the treatment of people with T2DM and led to the use of more intensive glycemic control in everyday clinical practice. As a result of this, three large clinical trials were initiated to determine whether intensive glycemic control had an impact on $\mathrm{CV}$ outcomes. These three trials were: ACCORD [14], ADVANCE [15], and VADT [16] (Table 1).

\section{ACCORD}

The ACCORD trial compared the effect of intensive (target $\mathrm{HbA}_{1 \mathrm{c}}<6.0 \%$ ) and standard therapy (target $\mathrm{HbA}_{1 \mathrm{c}} 7.0-7.9 \%$ ) in 10,251 people with T2DM and either established CVD or additional CV risk factors [14]. At the start of the trial, both the intensive and conventional treatment groups had poor glycemic control $\left(\mathrm{HbA}_{1 \mathrm{c}} 8.3 \pm 1.1 \%\right)$ and, after 1 year, both groups achieved stable $\mathrm{HbA}_{1 \mathrm{c}}$ levels $(6.4 \%$ and $7.5 \%$ in the intensive and conventional treatment groups, respectively). The ACCORD trial was terminated early, after 3.5 years' follow-up, owing to an increased risk of death in the intensive therapy arm [14]. Despite the increased risk of $\mathrm{CV}$ and all-cause mortality with intensive therapy, there was a trend toward reduced risk for the primary endpoint [combination of first occurrence of non-fatal MI or non-fatal stroke or death from CV causes; hazard ratio (HR) $(95 \% \mathrm{CI})=0.90(0.87-1.04)]$. The main cause of this reduced risk was a significant reduction in the risk of non-fatal MI with intensive treatment [HR $(95 \% \mathrm{CI})=0.76$ (0.62-0.92); $P=0.004$ ] [14]. This effect was only observed after about 3 years and the authors suggest that any benefits from intensive glycemic control might take several years to emerge [14]. There was a significant increase in risk for hypoglycemia $(P<0.001)$, as well as increased risk of weight gain of more than $10 \mathrm{~kg}$ $(P<0.001)$ with intensive treatment, and it has been suggested that these might both play a role in the increased mortality associated with intensive control.

Post hoc analyses were performed to investigate whether hypoglycemia was associated with this increased mortality. These analyses found that, even though severe hypoglycemia was associated with an increased risk of death in both study arms, the risk of death in people who experienced at least one severe hypoglycemic episode was lower with intensive control compared with standard care [18]. Conversely, a small but statistically significant inverse relationship between the number of symptomatic and unrecognized hypoglycemic episodes and the risk of death was observed with intensive control compared with standard care [19]. This relationship was, however, of uncertain clinical significance, suggesting that hypoglycemia was not the main driver for the increased mortality seen with intensive control [19]. 


\section{ADVANCE}

The ADVANCE trial compared the effect of standard glycemic control with intensive glycemic control [use of gliclazide (modified release) plus other drugs to target $\mathrm{HbA}_{1 \mathrm{c}} \leq 6.5 \%$ ] in 11,140 people with T2DM and either established macro- or microvascular disease or additional CV risk factors [15]. After 5 years, $\mathrm{HbA}_{1 \mathrm{c}}$ was lower with intensive control than with standard care $(6.53 \pm 0.91 \% \quad$ vs. $7.30 \pm 1.26 \%)$. There was no reduction in the risk of macrovascular events with intensive control compared with standard care [HR (95\% $\mathrm{CI})=0.94$ (0.84-1.06)]; however, there was a significant reduction in the risk of major microvascular events $[\mathrm{HR} \quad(95 \% \quad \mathrm{CI})=0.86$ (0.77-0.97); $P=0.01$ ] [15]. An increased risk for hypoglycemia and weight gain $(0.7 \mathrm{~kg}$ greater weight gain with intensive control vs. standard care; $P<0.001)$ was observed with intensive treatment.

A post hoc analysis found that severe hypoglycemia was associated with an increased risk for a number of adverse outcomes, including major macro- and microvascular events and mortality [20]. The authors of this analysis highlighted that, as there was no relationship between the number of severe hypoglycemic episodes and adverse event occurrence, it was possible that severe hypoglycemia only acted as a marker of vulnerability [20]. This suggests that even though hypoglycemia may be a contributor to adverse outcomes, there are likely other explanations for the inconsistent outcomes of these trials.

\section{VADT}

The VADT compared the effects of intensive (targeting a $1.5 \%$ decrease in $\mathrm{HbA}_{1 \mathrm{c}}$ ) and standard care on CV outcomes in 1,791 people with poorly controlled T2DM [21]. There was a decrease in $\mathrm{HbA}_{1 \mathrm{c}}$ observed at 3 months; by 6 months, this had stabilized, with $\mathrm{HbA}_{1 \mathrm{c}}$ levels being maintained in both groups for the remainder of the trial. There was a greater decrease in $\mathrm{HbA}_{1 \mathrm{c}}$ with intensive treatment and a $1.5 \%$ difference in $\mathrm{HbA}_{1 \mathrm{c}}$ levels was maintained from 6 months to the trial end [21]. No significant difference was observed between the intensive and standard care groups in the primary endpoint, which combined macrovascular and microvascular events and death from CV causes, and there was no difference between groups in death from any cause. There was a greater incidence of adverse events in the intensive therapy group compared with the standard care group $(24.1 \%$ vs. $17.6 \%$, respectively). The most frequent adverse event was hypoglycemia, which occurred significantly more frequently with intensive therapy $(P<0.001)[21]$.

\section{Meta-analyses of ACCORD, ADVANCE, VADT, and UKPDS}

The ACCORD, ADVANCE and VADT studies failed to demonstrate a reduction in $\mathrm{CV}$ mortality with more intensive glycemic control [14-16, 21]. There was a decrease in microvascular events in the ACCORD study, but no effect on macrovascular outcomes, confirming the results of the 10-year UKPDS $[12,14]$. No vascular benefit from intensive control was observed in ADVANCE or VADT $[15,21]$. Nonetheless, a meta-analysis including the 27,049 participants from the aforementioned trials (ACCORD, ADVANCE, UKPDS, and VADT) found a $9 \%$ risk reduction in major CV events (CV death or non-fatal MI or non-fatal stroke) with intensive therapy compared with standard therapy [HR (95\% 
CI $=0.91 \quad$ (0.84-0.99); Fig. 1] [21]. This reduction was primarily due to a $15 \%$ reduction in the risk of MI (fatal or non-fatal) with intensive therapy [HR $(95 \%$ CI $)=0.85$ (0.76-0.94)] [21]. Other meta-analyses investigating the effect of intensive glycemic control on CV outcomes have been performed, including UKPDS, ADVANCE, ACCORD, and VADT, as well as additional studies [22-26]. These analyses reach different conclusions depending on the trials included; however, overall, there appears to be evidence that intensive glycemic control provides limited CV benefits.

\section{Subanalyses of ACCORD, ADVANCE, VADT, and UKPDS}

Owing to the conflicting results from UKPDS, ACCORD, ADVANCE, and VADT, subgroup analyses have been performed to identify whether any subgroups experienced a benefit, which is masked by the presence of people who do not experience this benefit in the overall

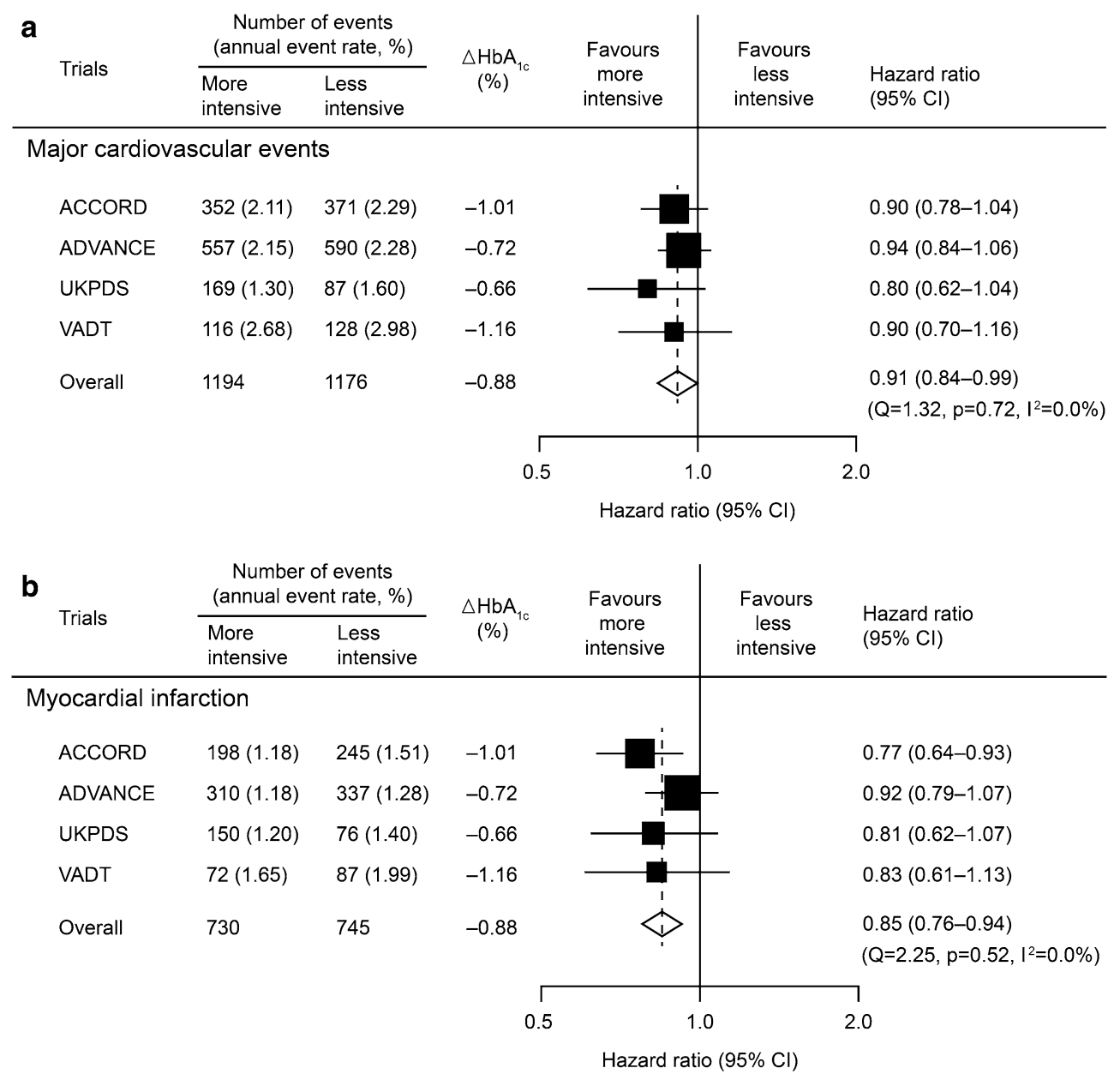

Fig. 1 The effects of intensive versus standard glycemic control on a major cardiovascular events (CV death or nonfatal MI or non-fatal stroke) and b MI (fatal or non-fatal) [21]. ACCORD Action to Control Cardiovascular Risk in Diabetes, ADVANCE Action in Diabetes and Vascular
Disease: Preterax and Diamicron MR Controlled Evaluation, $C I$ confidence interval, $C V$ cardiovascular, $H b A_{1 c}$ glycated hemoglobin, $M I$ myocardial infarction, UKPDS United Kingdom Prospective Diabetes Study, VADT Veteran Affairs Diabetes Trial 
population. Prespecified subgroup analyses of the ACCORD trial found that people receiving intensive therapy who had not experienced a previous $\mathrm{CV}$ event and those with $\mathrm{HbA}_{1 \mathrm{c}} \leq 8 \%$ may have experienced fewer fatal or non-fatal $\mathrm{CV}$ events than those receiving standard care ( $P=0.04$ and 0.03 , respectively) [14]. Subgroup analysis of the ADVANCE trial found that the results of intensive control were consistent for all subgroups [15].

The lack of agreement between UKPDS and the other trials (ACCORD, ADVANCE, and VADT) in terms of a reduction in CV risk, with intensive glycemic control in people with T2DM, is likely due to very different follow-up times between them, with only the UKPDS having a follow-up of more than 10 years compared with the shorter follow-up in the other studies [27]. Nevertheless, these studies and subanalyses of them highlighted that intensive glycemic control is not suitable for everyone, and the need for diabetes care to be personalized. This patient-centered approach to diabetes care was described by the American Diabetes Association (ADA)/European Association for the Study of Diabetes (EASD) in a joint consensus statement on the management of hyperglycemia [28]. This statement highlights that glycemic targets should be selected based on patient characteristics; for example, glycemic targets for frail elderly patients should be less strict than for younger patients owing to the increased risk of hypoglycemia with intensive control.

In addition to reducing blood glucose, therapies also have different effects as a result of their differing mechanisms of action. It has been suggested that the lack of agreement between trials investigating the effect of intensive glycemic control on $\mathrm{CV}$ outcomes may have been due to the use of different drugs and combinations of drugs [29-32]. Consequently, the therapies used either had a neutral effect on CV risk or produced adverse $\mathrm{CV}$ effects-for example, by inducing weight gain. It is, therefore, important that the $\mathrm{CV}$ effects of different therapies are determined to enable prescribers to choose the most effective treatments according to the needs of each individual.

\section{INSULIN AND CV OUTCOMES}

\section{Retrospective Studies}

Retrospective studies investigating the impact of insulin on $\mathrm{CV}$ outcomes have produced inconsistent results. A retrospective study published in 2004 by Nichols et al. [33] comparing 8,231 people with T2DM, with a matched cohort of people without diabetes, found that people with T2DM were 2.5-times more likely to develop congestive heart failure (CHF) than those without. When they compared the incidence of CHF with the therapies being used, they found that the addition of insulin increased the risk of $\mathrm{CHF}$ by 2.33 and 2.66 times compared with the addition of sulfonylurea or metformin, respectively [34]. A retrospective study by Margolis et al. [35] in 2008 examining 63,579 people with T2DM over 40 years of age during clinical practice also found that insulin may have a negative impact on CV outcomes. This study found that insulin use was associated with a 1.2-times greater risk of MI, with the risk increasing with longer use. These studies suggest that insulin has a negative impact on $\mathrm{CV}$ outcomes. However, a study published in 2012 by Hall et al. [36] investigating treatment intensification in 14,904 people with poorly controlled T2DM found that initiating insulin did not increase the incidence of macro- or 
microvascular events compared with the addition of an oral antidiabetic drug (OAD). In another study, Roumie et al. [37] compared time to $\mathrm{CV}$ events in a cohort of 178,000 metformin-treated patients who received either add-on insulin therapy or a sulfonylurea from 2001 to 2008 . The results showed that the addition of insulin or a sulfonylurea to patients receiving metformin was associated with an increased risk of a composite of non-fatal CV outcomes and all-cause mortality; the authors suggest that further study is warranted to better understand these associations. A retrospective analysis by Saleh et al. [38] found that, after a mean follow-up of 4.14 years, mortality rates for patients with T2DM who had undergone coronary angiography were highest in the insulin-treated, and insulin in combination with OAD groups compared to the other groups (diet only, OAD alone). Norhammar et al. [39] reviewed long-term mortality data from the Swedish Coronary Angiography and Angioplasty Registry in patients with and without T2DM after a first percutaneous coronary intervention (PCI). The authors concluded that not only was long-term mortality higher in patients with T2DM following a first PCI compared to patients without diabetes but that the mortality gap between the two groups increased with followup time. In another retrospective study, Raebel et al. [40] examined antihyperglycemic medication intensification treatment of patients with incident diabetes. The findings showed that insulin use was rarely considered as the first treatment intensification therapy for patients with diabetes on OADs. The authors surmise that this may be because some clinicians and patients are reluctant to initiate insulin due to the choice of OADs available; consequently, patient's and clinician's attitudes should be addressed accordingly. The conflicting results from retrospective studies have led to several prospective studies being undertaken to investigate whether insulin does have an effect on CV outcomes.

\section{Prospective Studies}

The Translating Research Into Action for Diabetes prospective observational study followed 8,334 people with T2DM over 8 years [41]. In this population, it was observed that the use of insulin monotherapy was associated with 1.24-times greater risk for all-cause mortality compared with OAD monotherapy [42]. However, combination therapy with OAD plus insulin was not associated with increased risk for overall mortality compared with the use of OADs alone. When $\mathrm{CV}$ and non-CV mortality were considered separately, the use of insulin was seen to be a risk factor for CV mortality but not nonCV mortality [42]. This highlights that the use of insulin is correlated with $\mathrm{CV}$ outcomes. This study did not investigate the different components of insulin therapy and it is possible that, as long-acting insulin analogs predominantly target FPG and rapid-acting analogs target postprandial glucose (PPG), they will have different $\mathrm{CV}$ effects. Another prospective observational study by Mellbin et al. [43] found that while there was no significant difference in mortality between insulin, metformin and sulfonylureas, a higher risk of non-fatal MI or stroke was observed in patients with T2DM receiving insulin. According to the study findings, after a median follow-up interval of 2.1 years, a protective effect was seen with metformin and an indeterminate response was observed with sulfonylureas.

\section{Rapid-acting Insulin Analogs}

The Nippon Ultra-Rapid Insulin and Diabetic Complication Evaluation study was a 5-year, 
open-label, randomized controlled trial that compared CV outcome in 325 Japanese people with T2DM intensively treated with either regular human insulin or insulin aspart [44]. The primary endpoint of this study was a composite CV endpoint, including $\mathrm{MI}$, angina pectoris, cerebral infarct/transient ischemic attack, coronary artery bypass graft, or PCI. A $43 \%$ reduction in the incidence of the primary composite endpoint was observed in people treated with insulin aspart compared with those treated with regular human insulin [6.4\% (12.8/ $1,000 /$ year $)$ vs. $11.3 \% \quad(22.2 / 1,000 /$ year $)$, respectively; $P<0.02$ ] [44]. There was no significant difference between groups for $\mathrm{HbA}_{1 \mathrm{c}}$ or FPG levels; however, 90-min PPG levels were significantly lower in the insulin aspart-treated group $(142 \pm 58 \mathrm{mg} / \mathrm{dL} \quad$ vs. $226 \pm 48 \mathrm{mg} / \mathrm{dL} ; P<0.02)$. This suggests that PPG levels could significantly contribute to CV risk.

The association between postprandial hyperglycemia and CV risk has been investigated in other studies. The Diabetes Intervention Study found that, over 11 years, 1-h post-breakfast blood glucose, but not FPG, was associated with a higher risk of MI and death in 1,139 newly diagnosed people with T2DM aged 30-55 years old [45]. The 14-year follow-up to the San Luigi Gonzago Diabetes Study that investigated 505 people with T2DM found that both $\mathrm{HbA}_{1 \mathrm{c}}$ and 2-h PPG levels were predictors of both $\mathrm{CV}$ events and all-cause mortality [46]. The DECODE study, which included 22,514 people with diabetes, also demonstrated that 2-h PPG was a better predictor of both all-cause and CV mortality compared with FPG [47].

The studies highlight that PPG plays an important role in $\mathrm{CV}$ risk and it has been suggested that this could occur because wide glycemic fluctuations induce oxidative stress that damages the vasculature [48]. However, guidelines recommend that insulin is initiated as a basal insulin analog to provide control of FPG and it is, therefore, important to understand whether it has any CV effects [28].

\section{Long-acting Insulin Analogs}

The ORIGIN study was designed in an attempt to determine whether insulin therapy can influence long-term CV outcomes [17]. ORIGIN was a 6-year, randomized, open-label, controlled, international, interventional study. The trial investigated whether insulin glargine, targeting normal FPG versus standard approaches to glycemia management, could reduce CV morbidity and/or mortality in people with early T2DM or prediabetes at high risk of $\mathrm{CV}$ events [17]. The ORIGIN study was the first large trial designed to specifically assess the impact of insulin on $\mathrm{CV}$ outcomes. Unlike ACCORD, ADVANCE, and VADT, ORIGIN studied patients with prediabetes or early T2DM; therefore, glucose control was more easily achieved and maintained [10-12]. The study also compared omega-3 polyunsaturated fatty acids (PUFAs) versus placebo in reducing $\mathrm{CV}$ events in the same population. A total of 12,537 people ( $\geq 50$ years of age, mean age 63.5 years, 35\% women) with evidence for either established CVD or a high-grade CVD risk factor, and with either prediabetes or early T2DM, were enrolled across 40 countries. At randomization, 82\% had established diabetes, $6 \%$ had newly diagnosed diabetes and $12 \%$ had impaired fasting glucose (IFG) or impaired glucose tolerance (IGT), mean duration of diabetes was 5.4 years. Mean FPG was $7.3 \mathrm{mmol} / \mathrm{L}$ and median $\mathrm{HbA}_{1 \mathrm{c}}$ level at baseline was $6.4 \%$ (interquartile range 5.8-7.2\%). Approximately two-thirds of participants had a previous history of CVD. 


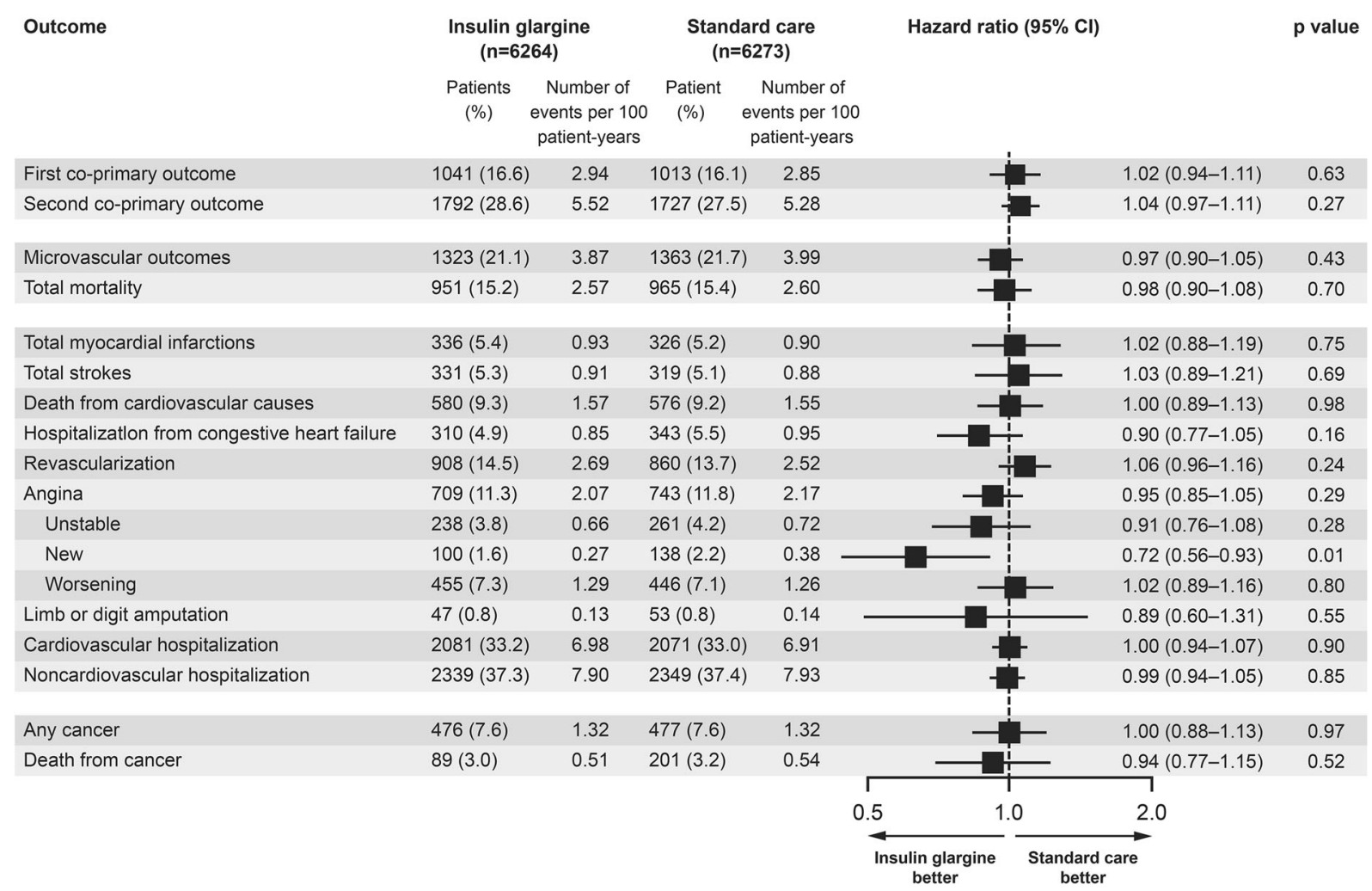

Fig. 2 Risk of cardiovascular outcomes in the ORIGIN trial-analysis for hazard ratio of insulin glargine versus standard care [17]. CI confidence interval, ORIGIN outcome reduction with initial insulin glargine. Reprinted from $N$ Engl J Med, ORIGIN trial investigators, basal

The two co-primary outcomes for insulin glargine versus standard care comparison were composites of major CV events. These were: (1) $\mathrm{CV}$ death, non-fatal MI or non-fatal stroke and (2) the same three events plus a revascularization procedure or hospitalization for heart failure. Additional outcomes of interest included total mortality (all causes), risk of diabetic microvascular outcomes and progression of IGT or IFG to T2DM. CV death was the primary outcome for the omega-3 PUFA comparison.

The final analysis, after a median follow-up of 6.2 years, included $>99 \%$ of participants and found that the incidence of both co-primary endpoints, or any of their component parts, did not differ significantly between insulin glargine insulin and cardiovascular and other outcomes in dysglycemia Volume No. 367, 319-328. Copyright (C) (2013) Massachusetts Medical Society. Reprinted with permission from Massachusetts Medical Society [17]

and standard care groups [HR: 1.02 (95\% CI $0.94-1.11 ; \quad P=0.63) \quad$ and $1.04 \quad(95 \% \quad$ CI 0.97-1.11; $P=0.27$ ) for co-primary endpoints 1 and 2, respectively; Fig. 2]. There was also no difference in mortality [HR: 0.98 (95\% CI 0.90-1.08); $P=0.70]$ or microvascular events [HR: 0.97 (95\% CI 0.90-1.05); $P=0.43$ ] between treatment arms. $\mathrm{HbA}_{1 \mathrm{c}}$ was lower with insulin glargine compared with standard of care, with a between-group difference of $0.3 \%(6.2 \%$ and $6.5 \%$ with glargine and standard of care, respectively). Of those with diabetes at baseline $60 \%$ and $45 \%$ of the insulin glargine and standard care groups, respectively, had $\mathrm{HbA}_{1 \mathrm{c}}<6.5 \%$ at 5 years [50]. Post hoc analysis found that people receiving insulin glargine were more likely to maintain $\mathrm{HbA}_{1 \mathrm{c}}<6.5 \%$ than 
people receiving standard care [OR: 2.98 (95\% CI 2.67-3.32); $P<0.001$ ] [50].

During the study, participants in the insulin glargine group experienced modest weight gain (median change: +1.6 vs. $-0.5 \mathrm{~kg}$ for insulin glargine and standard care, respectively) and more episodes of hypoglycemia (rate of severe hypoglycemia 0.01 vs. 0.0031 per person-year for insulin glargine and standard care, respectively) than the standard care group, both of which have been linked to increased $\mathrm{CV}$ outcomes in epidemiological studies. In a post hoc analysis, severe hypoglycemia was found to be associated with a greater risk for co-primary outcome, mortality, CV death, and arrhythmic death [51]. Nonetheless, the relative risk of $\mathrm{CV}$ outcomes with hypoglycemia was lower with insulin glargine than with standard care, highlighting that insulin glargine itself does not affect $\mathrm{CV}$ outcomes.

There was no overall increase in CV outcomes in this study despite increased hypoglycemia and weight gain with insulin glargine treatment, suggesting either that these adverse effects do not cause these outcomes or that any potential harm was offset by a treatment benefit. This beneficial effect is unlikely to be associated with concomitant treatment, as more metformin was used in the standard of care than the insulin glargine arm, suggesting that any treatment benefit was related to insulin glargine itself.

Owing to its design, the ORIGIN study looked specifically at the $\mathrm{CV}$ outcomes of insulin glargine treatment and not at the effect of improved glycemic control, and found no association between insulin glargine and $\mathrm{CV}$ outcomes. This suggests that the $\mathrm{CV}$ benefits reported in previous small-scale or long-term follow-up studies might be related to the metabolic effects of treatment, rather than the insulin itself. Alternatively, it could be that ORIGIN was not of sufficient duration to show a modulation of $\mathrm{CV}$ outcomes that may take more than a decade to manifest.

The near normal median $\mathrm{HbA}_{1 \mathrm{c}}$ level at baseline in the ORIGIN study population helped to minimize any bias in the findings against insulin. Despite the benefits of early insulin initiation, patients are frequently placed on insulin therapy much later in the disease course of diabetes when the burden of illness is higher and $\mathrm{HbA}_{1 \mathrm{c}}$ levels are uncontrolled on OADs. In these instances, patients receiving insulin therapy may be viewed as a proxy for 'worse disease' and could therefore confound any results against insulin in favor of other therapies. The objective of the ORIGIN trial was not to demonstrate whether insulin improved glycemic control in patients with near normal $\mathrm{HbA}_{1 \mathrm{c}}$ levels but to determine the effect of insulin, if any, on CV outcomes in patients with early and mild diabetes.

A recently published sub-study of the ORIGIN trial used continuous glucose monitoring in a subset of subjects to examine glycemic variability, PPG effects and hypoglycemia after 2 years of treatment. Findings indicate that treatment to target FPG $<5.3 \mathrm{mmol} / \mathrm{L}$ with insulin glargine was not associated with a modestly increased risk of hypoglycemia. Furthermore, strict control of FPG was effective in controlling PPG excursions [49].

Even though several large prospective clinical trials have been carried out, and demonstrate that insulin glargine has a neutral effect on $\mathrm{CV}$ outcomes, there are a number of important questions that remain unanswered. Further analyses from the ORIGIN extension study [Outcome Reduction with an Initial Glargine Intervention and Legacy Effect (ORIGINALE)] and the Cardiovascular Risk 
Evaluation in people with type 2 Diabetes on Insulin Therapy (CREDIT) study, will provide further information on the long-term $\mathrm{CV}$ and general safety profiles of insulin therapy. The results for insulin glargine need to be expanded to cover other long-acting insulin analogs, and the extent to which FPG contributes to CV risk needs to be determined. In addition, if insulin is found to have effects on $\mathrm{CV}$ risk beyond glycemic control in these trials, the mechanism by which insulin could be providing additional $\mathrm{CV}$ protection would need to be determined.

\section{DISCUSSION}

Diabetes is an independent risk factor for $\mathrm{CV}$ events; however, it is often associated with a number of comorbidities including obesity. These comorbidities can themselves be risk factors for $\mathrm{CV}$ events, making it difficult to determine the impact of diabetes treatment on $\mathrm{CV}$ risk. However, long-term prospective studies have demonstrated that maintaining glycemic control at the levels recommended by the ADA and EASD $\left(\mathrm{HbA}_{1 \mathrm{c}}<7 \%\right)$ results in a clinically relevant decrease in $\mathrm{CV}$ risk [28].

The optimization of glycemic control, should, therefore, be emphasized for people with diabetes to reduce the risk of $\mathrm{CV}$ outcomes. However, only $35.6-50.0 \%$ of people in the USA reach glycemic targets of $\mathrm{HbA}_{1 \mathrm{c}}<7 \%$ as suggested by the ADA and EASD [28, 52]. This is, therefore, increasing the risk of $\mathrm{CV}$ events in a large proportion of people with diabetes. This poor control could result from a number of factors, including clinical inertia and poor adherence to treatment or blood glucose monitoring; therefore, it is important that the reason for poor glycemic control is determined, enabling the treatment to be individualized, thus ensuring that it has maximal impact. This could include patient education programs, the use of insulin pen devices rather than vial and syringe, and patient-led titration of insulin. The results of the ORIGIN study demonstrate that insulin glargine has no effect on CV outcomes, and the improved outcomes that result from optimal glycemic control suggest that treatment should be intensified when glycemic control worsens to maintain treatment benefits, including the use of insulin as recommended by the ADA/EASD consensus statement [28].

The ADA/EASD recommends that people with T2DM receive a multifaceted therapy program comprising various $\mathrm{CV}$ risk reduction strategies, such as lipid- and blood-pressurelowering therapies, as appropriate $[53,54]$. The STENO-2 study demonstrated that the use of intensive multifactorial treatment had sustained beneficial effects on the incidence of vascular complications, as well as rates of allcause and CV-related mortality [54]. Despite the evidence of the effectiveness of combination therapy, $40-88 \%$ of people with diabetes worldwide are undertreated [55]. This is clearly an unmet need in the treatment of T2DM.

Effective glycemic control, targeting normoglycemia, is essential for people with diabetes as it reduces the risk of $\mathrm{CV}$ complications and mortality. The importance of optimal glycemic control was underscored by the UKPDS, which transformed the way in which diabetes is treated. Subsequently, a series of large prospective clinical trials were performed (ACCORD, ADVANCE, and VADT) that investigated the impact of intensive glycemic control on $\mathrm{CV}$ outcomes. Although the trials produced inconsistent results and a definite benefit of intensive control could not be determined, meta-analyses including these trials suggest that there is a benefit, in particular a reduction in the incidence of non-fatal MI. Indeed, sub-studies of the ACCORD and 
ADVANCE trials demonstrated that intensive glycemic control is not beneficial for everybody and highlighted the need for personalized care in T2DM. In addition, it was important to determine which treatments would be beneficial for specific subpopulations of people with diabetes. The ORIGIN trial, the first largescale trial specifically investigating the impact of insulin on CV outcomes, demonstrated that insulin glargine was CV neutral in people with IGT and early diabetes and that the beneficial effects seen were predominantly a result of improved glycemic control. However, the possibility that treatment with insulin glargine has additional $\mathrm{CV}$ effects beyond glycemic control has not been ruled out.

While there are studies that have suggested a possible increase in $\mathrm{CV}$ risk associated with insulin use in patients with T2DM, it is important to highlight that despite the benefits of early insulin use, insulin therapy is often reserved for patients with advanced and long-standing diabetes that is uncontrolled with OADs. Such a population, as a course of their uncontrolled disease, would be expected to be at increased risk of microvascular disease, making it difficult to determine whether the increased risk is attributed to insulin therapy or the study population itself. In addition, the lack of consistent, and often contradictory, findings regarding the effect of insulin on $\mathrm{CV}$ outcomes in both retrospective and prospective studies highlights the need for more rigorous research to be carried out in the form of a RCT. A key limitation of these studies, acknowledged by the authors themselves, is the short duration of follow-up and it is clear that further research needs to be done in this area with a longer duration of follow-up to truly ascertain the extent of the relationship between insulin treatment and $\mathrm{CV}$ outcomes in the long term.

\section{CONCLUSION}

Optimal glycemic control in people with T2DM should be determined on a case-by-case basis dependent on each individual's characteristics. In people with $\mathrm{CV}$ risk factors, optimal glycemic control should be supplemented by a multifactorial approach targeting known $\mathrm{CV}$ risk factors (including hypertension, hypercholesterolemia, and hyperlipidemia). An individualized approach targeting both glycemic control and CV risk factors should enable the best outcome to be obtained in every person with T2DM.

\section{ACKNOWLEDGMENTS}

Article processing charges for this study were funded by Sanofi, Bridgewater, New Jersey, USA. Editorial support was provided by Alexander Jones and Lisa Langley, Discovery London, and funded by Sanofi. All named authors meet the ICMJE criteria for authorship for this manuscript, take responsibility for the integrity of the work as a whole, and have given final approval for the version to be published.

Conflict of interest. George Dailey is a member of the speakers bureau for Merck (Januvia), Sanofi (Lantus \& Apidra), and AstraZeneca (Onglyza, Bydureon, Farxiga); he has been an investigator for GlaxoSmithKline, Novo Nordisk, Roche, Halozyme, Gilead, and Hammi; he is occasionally a consultant for Sanofi. Edward Wang was an employee of Sanofi at the time the manuscript was developed.

Compliance with ethics guidelines. The analysis in this article is based on previously 
conducted studies, and does not involve any new studies of human or animal subjects performed by any of the authors.

Open Access. This article is distributed under the terms of the Creative Commons Attribution Noncommercial License which permits any noncommercial use, distribution, and reproduction in any medium, provided the original author(s) and the source are credited.

\section{REFERENCES}

1. Gu K, Bainbridge B, Darveau RP, Page RC. Antigenic components of Actinobacillus actinomycetemcomitans lipopolysaccharide recognized by sera from patients with localized juvenile periodontitis. Oral Microbiol Immunol. 1998;13:150-7.

2. Fox CS, Coady S, Sorlie PD, et al. Increasing cardiovascular disease burden due to diabetes mellitus: the Framingham Heart Study. Circulation. 2007;115:1544-50.

3. Paynter NP, Mazer NA, Pradhan AD, Gaziano JM, Ridker PM, Cook NR. Cardiovascular risk prediction in diabetic men and women using hemoglobin A1c vs. diabetes as a high-risk equivalent. Arch Intern Med. 2011;171:1712-8.

4. Stevens RJ, Kothari V, Adler AI, Stratton IM, United Kingdom Prospective Diabetes Study G. The UKPDS risk engine: a model for the risk of coronary heart disease in Type II diabetes (UKPDS 56). Clin Sci (Lond). 2001;101:671-9.

5. Zethelius B, Eliasson B, Eeg-Olofsson K, et al. A new model for 5-year risk of cardiovascular disease in type 2 diabetes, from the Swedish National Diabetes Register (NDR). Diabetes Res Clin Pract. 2011;93:276-84.

6. Goff DC Jr, Lloyd-Jones DM, Bennett G, et al. 2013 ACC/AHA guideline on the assessment of cardiovascular risk: a report of the American College of Cardiology/American Heart Association Task Force on Practice Guidelines. Circulation. 2014;129:S49-73.

7. Borg R, Kuenen JC, Carstensen B, et al. $\mathrm{HbA}(1)(\mathrm{c})$ and mean blood glucose show stronger associations with cardiovascular disease risk factors than do postprandial glycaemia or glucose variability in persons with diabetes: the A1CDerived Average Glucose (ADAG) study. Diabetologia. 2011;54:69-72.

8. Cederholm J, Zethelius B, Nilsson PM, et al. Effect of tight control of HbA1c and blood pressure on cardiovascular diseases in type 2 diabetes: an observational study from the Swedish National Diabetes Register (NDR). Diabetes Res Clin Pract. 2009;86:74-81.

9. Eeg-Olofsson K, Cederholm J, Nilsson PM, et al. New aspects of HbA1c as a risk factor for cardiovascular diseases in type 2 diabetes: an observational study from the Swedish National Diabetes Register (NDR). J Intern Med. 2010;268:471-82.

10. American Diabetes A. Standards of medical care in diabetes-2013. Diabetes Care. 2013;36(Suppl 1): S11-66.

11. Holden SE, Gale EA, Jenkins-Jones S, Currie CJ. How many people inject insulin? UK estimates from 1991 to 2010. Diabetes Obes Metab. 2014;16:553-9.

12. UK Prospective Diabetes Study. UKPDS) Group. Intensive blood-glucose control with sulphonylureas or insulin compared with conventional treatment and risk of complications in patients with type 2 diabetes (UKPDS 33. Lancet. 1998;352:837-53.

13. Holman RR, Paul SK, Bethel MA, Matthews DR, Neil HA. 10-year follow-up of intensive glucose control in type 2 diabetes. $\mathrm{N}$ Engl J Med. 2008;359:1577-89.

14. Gerstein HC, Miller ME, Byington RP, et al. Effects of intensive glucose lowering in type 2 diabetes. N Engl J Med. 2008;358:2545-59.

15. Advance Collaborative Group, Patel A, MacMahon $S$, et al. Intensive blood glucose control and vascular outcomes in patients with type 2 diabetes. N Engl J Med. 2008;358:2560-72.

16. Duckworth W, Abraira C, Moritz T, et al. Glucose control and vascular complications in veterans with type 2 diabetes. $\mathrm{N}$ Engl J Med. 2009;360:129-39.

17. Origin Trial Investigators, Gerstein HC, Bosch J, et al. Basal insulin and cardiovascular and other outcomes in dysglycemia. $\mathrm{N}$ Engl J Med. 2012;367:319-28.

18. Bonds DE, Miller ME, Bergenstal RM, et al. The association between symptomatic, severe hypoglycaemia and mortality in type 2 diabetes: retrospective epidemiological analysis of the ACCORD study. BMJ. 2010;340:b4909. 
19. Seaquist ER, Miller ME, Bonds DE, et al. The impact of frequent and unrecognized hypoglycemia on mortality in the ACCORD study. Diabetes Care. 2012;35:409-14.

20. Zoungas S, Patel A, Chalmers J, et al. Severe hypoglycemia and risks of vascular events and death. N Engl J Med. 2010;363:1410-8.

21. Control G, Turnbull FM, Abraira C, et al. Intensive glucose control and macrovascular outcomes in type 2 diabetes. Diabetologia. 2009;52:2288-98.

22. Zhang C, Zhou YH, Xu CL, Chi FL, Ju HN. Efficacy of intensive control of glucose in stroke prevention: a meta-analysis of data from 59,197 participants in 9 randomized controlled trials. PLoS One. 2013;8:e54465.

23. Boussageon R, Bejan-Angoulvant $\mathrm{T}$, Saadatian-Elahi $M$, et al. Effect of intensive glucose lowering treatment on all cause mortality, cardiovascular death, and microvascular events in type 2 diabetes: meta-analysis of randomised controlled trials. BMJ. 2011;343:d4169.

24. Mannucci E, Monami M, Lamanna C, Gori F, Marchionni N. Prevention of cardiovascular disease through glycemic control in type 2 diabetes: a meta-analysis of randomized clinical trials. Nutr Metab Cardiovasc Dis. 2009;19:604-12.

25. Ray KK, Seshasai SR, Wijesuriya S, et al. Effect of intensive control of glucose on cardiovascular outcomes and death in patients with diabetes mellitus: a meta-analysis of randomised controlled trials. Lancet. 2009;373:1765-72.

26. Hemmingsen B, Lund SS, Gluud C, et al. Intensive glycaemic control for patients with type 2 diabetes: systematic review with meta-analysis and trial sequential analysis of randomised clinical trials. BMJ. 2011;343:d6898.

27. Dailey G. Overall mortality in diabetes mellitus: where do we stand today? Diabetes Technol Ther. 2011;13(Suppl 1):S65-74.

28. Inzucchi SE, Bergenstal RM, Buse JB, et al. Management of hyperglycemia in type 2 diabetes: a patient-centered approach: position statement of the American Diabetes Association (ADA) and the European Association for the Study of Diabetes (EASD). Diabetes Care. 2012;35:1364-79.

29. Kishore P, Kim SH, Crandall JP. Glycemic control and cardiovascular disease: what's a doctor to do? Curr Diab Rep. 2012;12:255-64.

30. Giorgino F, Leonardini A, Laviola L. Cardiovascular disease and glycemic control in type 2 diabetes: now that the dust is settling from large clinical trials. Ann N Y Acad Sci. 2013;1281:36-50.

31. Miller M. Dyslipidemia and cardiovascular risk: the importance of early prevention. QJM. 2009;102: 657-67.

32. Hobbs FD. Reducing cardiovascular risk in diabetes: beyond glycemic and blood pressure control. Int J Cardiol. 2006;110:137-45.

33. Nichols GA, Gullion CM, Koro CE, Ephross SA, Brown JB. The incidence of congestive heart failure in type 2 diabetes: an update. Diabetes Care. 2004;27:1879-84.

34. Nichols GA, Koro CE, Gullion CM, Ephross SA, Brown JB. The incidence of congestive heart failure associated with antidiabetic therapies. Diabetes Metab Res Rev. 2005;21:51-7.

35. Margolis DJ, Hoffstad O, Strom BL. Association between serious ischemic cardiac outcomes and medications used to treat diabetes. Pharmacoepidemiol Drug Saf. 2008;17:753-9.

36. Hall GC, McMahon AD, Carroll D, Home PD. Macrovascular and microvascular outcomes after beginning of insulin versus additional oral glucoselowering therapy in people with type 2 diabetes: an observational study. Pharmacoepidemiol Drug Saf. 2012;21:305-13.

37. Roumie CL, Greevy RA, Grijalva CG, et al. Association between intensification of metformin treatment with insulin vs. sulfonylureas and cardiovascular events and all-cause mortality among patients with diabetes. JAMA. 2014;311:2288-96.

38. Saleh N, Petursson P, Lagerqvist B, et al. Long-term mortality in patients with type 2 diabetes undergoing coronary angiography: the impact of glucose-lowering treatment. Diabetologia. 2012;55:2109-17.

39. Norhammar A, Lagerqvist B, Saleh N. Long-term mortality after PCI in patients with diabetes mellitus: results from the Swedish Coronary Angiography and Angioplasty Registry. EuroIntervention. 2010;5:891-7.

40. Raebel MA, Ellis JL, Schroeder EB, et al. Intensification of antihyperglycemic therapy among patients with incident diabetes: a surveillance prevention and management of diabetes mellitus (SUPREME-DM) study. Pharmacoepidemiol Drug Saf. 2014;23:699-710.

41. TRIAD Study Group. The Translating Research Into Action for Diabetes (TRIAD) study: a multicenter 
study of diabetes in managed care. Diabetes Care. 2002;25:386-9.

42. McEwen LN, Karter AJ, Waitzfelder BE, et al. Predictors of mortality over 8 years in type 2 diabetic patients: translating research into action for diabetes (TRIAD). Diabetes Care. 2012;35:1301-9.

43. Mellbin LG, Malmberg K, Norhammar A, Wedel H, Rydén L, DIGAMI 2 Investigators. The impact of glucose lowering treatment on long-term prognosis in patients with type 2 diabetes and myocardial infarction: a report from the DIGAMI 2 trial. Eur Heart J. 2008;29:166-76.

44. Pollock RF, Valentine WJ, Pilgaard T, Nishimura H. The cost effectiveness of rapid-acting insulin aspart compared with human insulin in type 2 diabetes patients: an analysis from the Japanese third-party payer perspective. J Med Econ. 2011;14:36-46.

45. Hanefeld M, Fischer S, Julius U, et al. Risk factors for myocardial infarction and death in newly detected NIDDM: the diabetes intervention study, 11-year follow-up. Diabetologia. 1996;39:1577-83.

46. Cavalot F, Pagliarino A, Valle M, et al. Postprandial blood glucose predicts cardiovascular events and all-cause mortality in type 2 diabetes in a 14-year follow-up: lessons from the San Luigi Gonzaga Diabetes Study. Diabetes Care. 2011;34:2237-43.

47. Decode Study Group tEDEG. Glucose tolerance and cardiovascular mortality: comparison of fasting and 2-hour diagnostic criteria. Arch Intern Med. 2001;161:397-405.

48. Monnier L, Mas E, Ginet C, et al. Activation of oxidative stress by acute glucose fluctuations compared with sustained chronic hyperglycemia in patients with type 2 diabetes. JAMA. 2006;295:1681-7.

49. Hanefeld M, Koehler C, Hoffmann C, Wilhelm K, Kamke W, Gerstein H. Effect of targeting normal fasting glucose levels with basal insulin glargine on glycaemic variability and risk of hypoglycaemia: a randomized, controlled study in patients with early Type 2 diabetes. Diabet Med. 2010;27:175-80.

50. Origin Trial Investigators. Characteristics associated with maintenance of mean $\mathrm{A} 1 \mathrm{C}<6.5 \%$ in people with dysglycemia in the ORIGIN trial. Diabetes Care. 2013;36:2915-22.

51. Origin Trial Investigators. Does hypoglycaemia increase the risk of cardiovascular events? A report from the ORIGIN trial. Eur Heart J. 2013;34:3137-44.

52. Esposito K, Giugliano D. Current insulin analogues in the treatment of diabetes: emphasis on type 2 diabetes. Expert Opin Biol Ther. 2012;12:209-21.

53. Gaede P, Vedel P, Larsen N, Jensen GV, Parving HH, Pedersen O. Multifactorial intervention and cardiovascular disease in patients with type 2 diabetes. N Engl J Med. 2003;348:383-93.

54. Gaede P, Lund-Andersen H, Parving HH, Pedersen O. Effect of a multifactorial intervention on mortality in type 2 diabetes. $\mathrm{N}$ Engl J Med. 2008;358:580-91.

55. Gakidou E, Mallinger L, Abbott-Klafter J, et al. Management of diabetes and associated cardiovascular risk factors in seven countries: a comparison of data from national health examination surveys. Bull World Health Organ. 2011;89:172-83. 